\title{
Editorial
}

\section{Slang and profanity: poor moderation and journalistic / editorial standards by Retraction Watch} Teixeira da Silva JA

Bangladesh Journal of Medical Science Vol. 16 No. 01 January'17. Page : 5-9

One expects professional journalism to operate to the same high standards as science publishing. Such standards include appropriate tone and language. In recent years, science has come under increased scrutiny and attention, and dozens of critical blogs have mushroomed, some with a distinctly antiscience agenda. One in particular has excelled above all others and stands out. Prominent, web trafficattracting Retraction Watch (http://retractionwatch. $\underline{\mathrm{com}})$ is a blog whose heading motto is "Tracking retractions as a window into the scientific process." Certainly, from this statement, the claims appear to be noble. And, as an example, like noble journals like Nature published by Nature Publishing Group, which Retraction Watch actively tracks, monitors and archives (http://retractionwatch.com/category/ by-journal/nature-retractions/), one expects that the scientific standards that Retraction Watch expects from scientists and journals would also apply to this blog and its journalists as well. One of the most important issues that defines the classy and professional nature of a scientific journal is its tone and language with the public. Slang, rudeness and inappropriate language are not tolerated and are immediately moderated out of the conversation and most certainly do not appear in scientific papers. On occasion, and as a great exception to the rule, one may find slang or inappropriate language in journals that do not pride themselves in clean and decent language, or that have no professional academic standards. One such case is the spoof paper entitled "Get Me Off Your Fucking Mailing List", originally written by David Mazières and Eddie Kohler, submitted by Dr. Peter Vamplew of Federation University Australia's School of Engineering and Information Technology in response to spam that he had received, and accepted by the International Journal of Advanced Computer Technology (http:// www.ijact.org/index.htm), a "predatory" journal ${ }^{1}$. It is more than evident that such disgraceful language should never be present in a scientific paper and that such language should be immediately eschewed by scholarly journals and blogs.

The founders and current leadership of Retraction Watch, Dr. Ivan Oransky and Dr. Adam Marcus, hold scientists, editors, journals and publishers to extremely high standards. Often placed under the microscope, these entities are regularly grilled about their lack of standards. And, when those standards do not seem to satisfy the extremely highly professional standards imposed by the Oransky + Marcus team, that entity will be profiled, even if it has nothing to do with retractions, the focus of the blog. Knowing that such high standards exist, readers will surely be shocked to learn of the blatant and crude slang used by Marcus - when there are so many other appropriate terms that could have been used - to describe his views if irony has a place in science ${ }^{2}$. In his story, Marcus introduces the topic as "metabullshit" (Fig. 1).

Correspondence to: Jaime A. Teixeira da Silva, P. O. Box 7, Miki-cho post office, Ikenobe 3011-2, Kagawa-ken, 761-0799, Japan; jaimetex@yahoo.com 


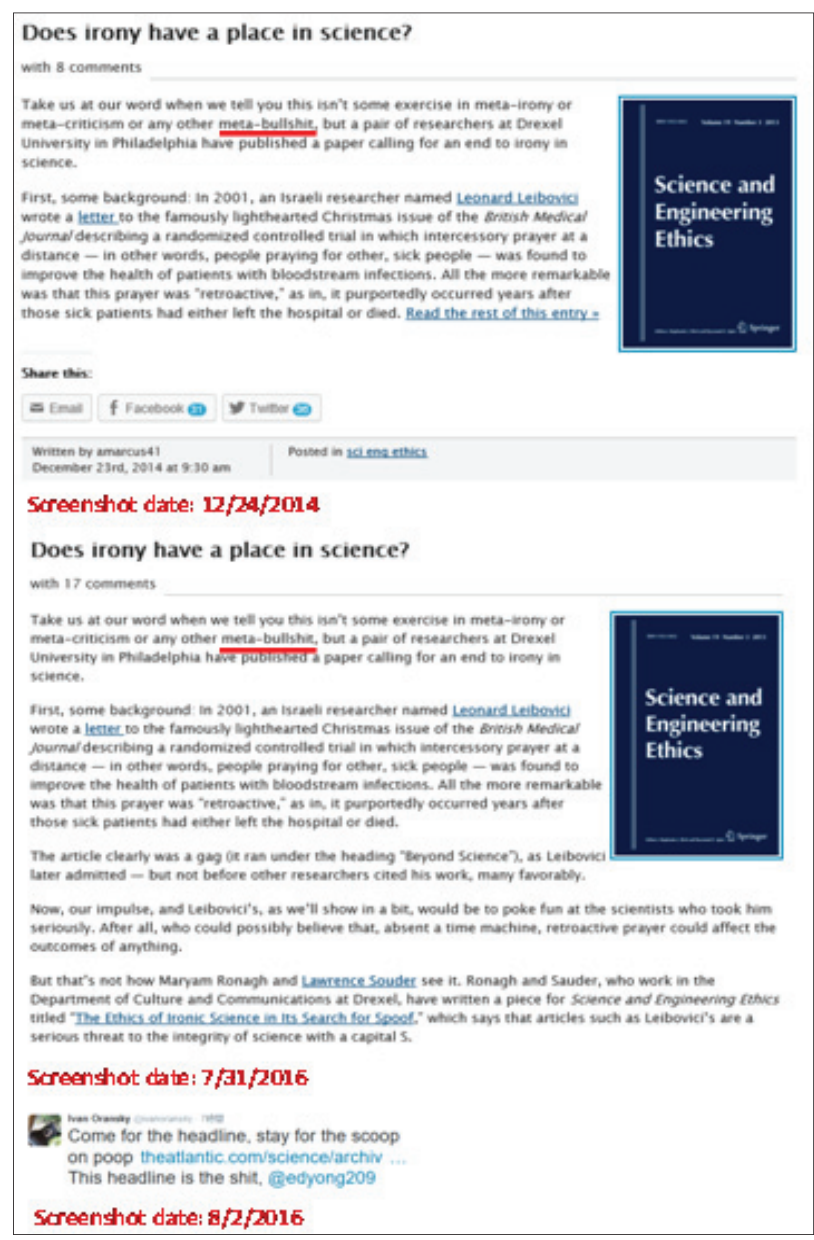

Fig. 1 Screenshot of unmoderated slang by Adam Marcus and Ivan Oransky, the co-leaders of Retraction Watch. Red underbar indicates profanity. From Marcus (2014).

This use of profanity is also popular with the cofounder, Oransky, who describes the headline of an article in The Atlantic.com in a Tweet as "This headline is the shit" (Fig. 1, bottom). The literary writing skills of Retraction Watch that seem to require profanity for their stories to achieve success and wide readership, seems to be consistent (Fig. 2) ${ }^{3}$.

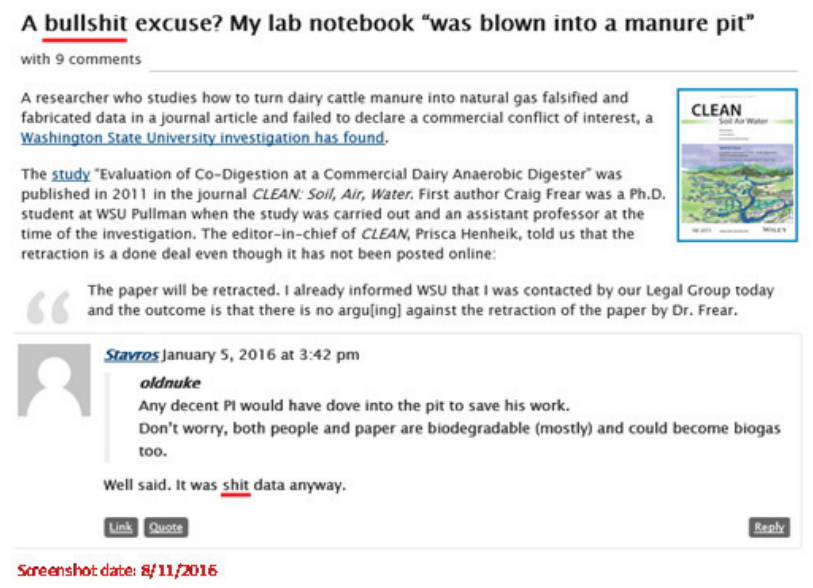

Fig. 2 Profanity used by Retraction Watch writer, Brendan Borrell, is consistent with the pleasant use of similar profanity by its founder's Ivan Oransky and Adam Marcus. Red underbar indicates profanity. From Borrell (2016).

Both the story title and the commentator's profanity could only have been actively approved by the Retraction Watch moderators, Oransky and Marcus, i.e., there is no excuse for "accidental" approval. Immediately, one would associate such rude language with low-class web-sites or blogs, but never with Retraction Watch's expected high journalistic standards. It is not clear how frequently Oransky and Marcus and their team of "journalists" use such bad language and slang, or if they cover up their tracks to avoid scrutiny - another undocumented unprofessional issue with this blog - but the message should be clear: scientists and the scientific community should not have to tolerate bad language by these so-called science journalists and watchdogs when describing science, and should hold these journalists to equally high scrutiny as we are held. A zero tolerance towards bad language and profanity must work both ways to merit respect.

Readers may argue that this is simply an expression of freedom of speech or poetic license, but in fact, it simply reveals poor poetic skills and even lower journalistic standards. What will be curious - and even ironic - is if Retraction Watch will issue an erratum to remove this slang by the co-founders, Oransky and Marcus, from their blog and from Twitter, and to disavow its future use, to be consistent with their expectations of scientists when errors or similar inappropriate language are discovered in the published scientific literature. If Retraction Watch does not correct this bad language, then not only shows that they openly embrace slang and profanity, but that they also practice double standards, i.e., they expect authors and editors to be respectful and to correct errors or moderate bad language, when they themselves do not.

There is one case where Retraction Watch deleted reader profanity (Fig. 3) from the comment section of a blog post ${ }^{4}$, only after a complaint comment was made, but the complaint and the appropriate correction were not published. 


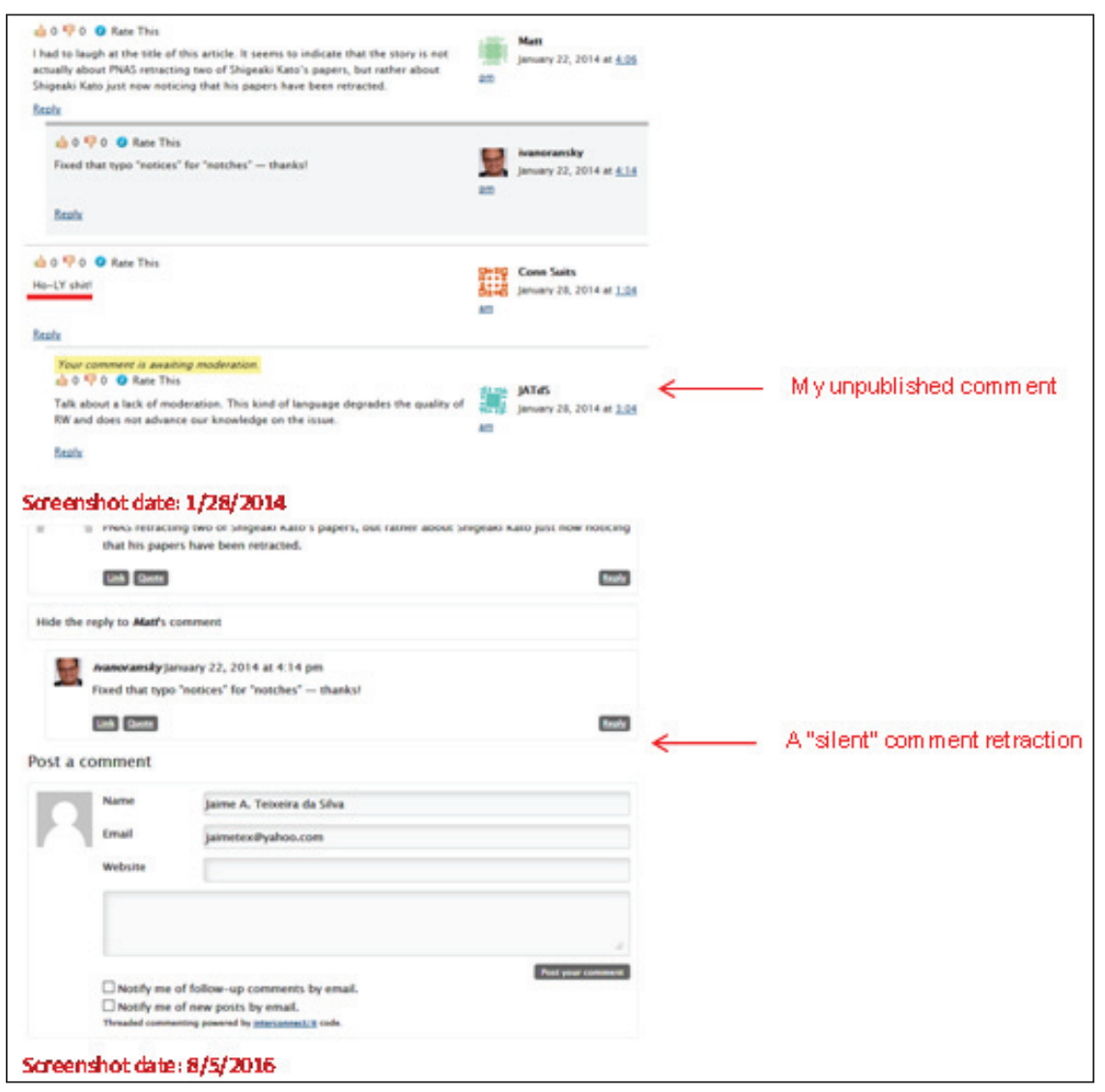

Fig. 3 The manner in which Retraction Watch corrects commentator profanity is incompatible with the expectations they hold of scientists correction of their literature. Red underbar indicates profanity. From Oransky (2014).

In this case, the manner in which the profanity was simply erased, equivalent to a silent retraction ${ }^{5}$, indicates that the Retraction Watch team holds scientists and itself to different morals, and screening and correction standards. It also indicates a dishonest editing behavior by Retraction Watch, in this case, the author of this article, Ivan Oransky ${ }^{6}$. For example, had, for some odd or unknown reason, profanity been used by - or slipped into the manuscript by mistake, either by the author or unnoticed by the editor - in a published scientific paper, then without a doubt that a responsible editor and publisher would do one of two things: a) it would issue an erratum to indicate that it had shown oversight during copy-editing; $b$ ) it would issue a retraction as an acknowledgement that it does not show tolerance to such profanity in public documents. The correct thing to have done would thus have been to leave the original comment, included my public complaints, subsequently added a strikethrough to the profanity, and an editorial note indicating that the profanity was cut and an apology for poor screening allowing such language to enter the discussion arena. It is curious that the comment above the profanity-laced commentator comment alluded to a hilarious pun in the title caused by an incorrect choice of word, namely "notices" instead of "notches". Although no screenshot exists of this poor editorial gaffe, the error remains in the stories URL, as "notices". The dangerous aspect of this edit is the ability of Oransky and Marcus to edit the titles of their stories with a simple click or two. Can the readership imagine the scandal if the published scientific record could be so simply, or easily, edited by the editor-inchief, without a formal erratum or corrigendum? If that were to take place in the scientific literature, that would invoke an uproar by the Oransky/Marcus couple.

Sadly, Retraction Watch's founders, Oransky and Marcus, and their team of ethics vigilantes, disguised as science journalists, are a notch above the rest of the ethically peasant scientific community, and it is thus difficult - if not impossible, given their popularity, funding and highlevel connections - to hold them as accountable as they are trying to hold the scientific community accountable.

There is a curious silver lining to this account. Soon after Retraction Watch received hundreds of thousands of US\$ in "charity" - awarded to its pseudo "parent organization" Center for Science Integrity by the MacArthur Foundation - it mysteriously started to cut back on published comments. When questioned about the excessive red tape that was being employed and the stifling of a robust and balanced public discussion, the public was offered the excuse that there was no time to screen and manage commentator comments. Comment truncation - as opposed to comment moderation - is potentially one way of eliminating the risk of letting through commentator profanity. Is it possible, as evidenced by a recent post by Adam Marcus ${ }^{7}$, that some moderate level of self-moderation has evolved, as exemplified by the substitution of a likely " $F$ "word by “@\#\$(@*\#\$@” (Fig. 4)? 


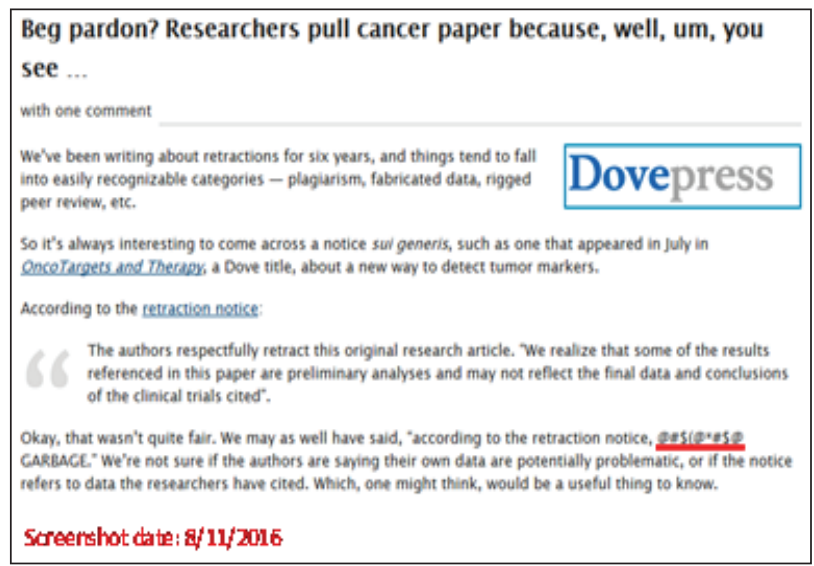

Fig. 4 Is Adam Marcus, a Retraction Watch co-founder, finally evolving a sense of self-moderation? Red underbar indicates profanity. Screenshot from Marcus (2016).

Sadly, this hypothesis has proven false as the latest "Weekend reads" shows, with part of the title reading "is science fucked?", raising the ire of some commentators whose critiques were surprisingly published (Fig. 5).

In order for Retraction Watch to instill a culture of mutual respect, it must engage in the language of respect. And that involves not using slang and profanity to express their ideas. It's very easy, and tempting, to use slang to express one's ideas, even more so knowing that shocking titles and language will attract greater readership, but is this the ambience that scientists want to use as their platform for engaging problems related to science, or do scientists wish to engage instead with professional journalists who prefer, instead, to choose a higher moral road? As it currently stands, the fairly regular use of slang and profanity by Retraction Watch decreases respect

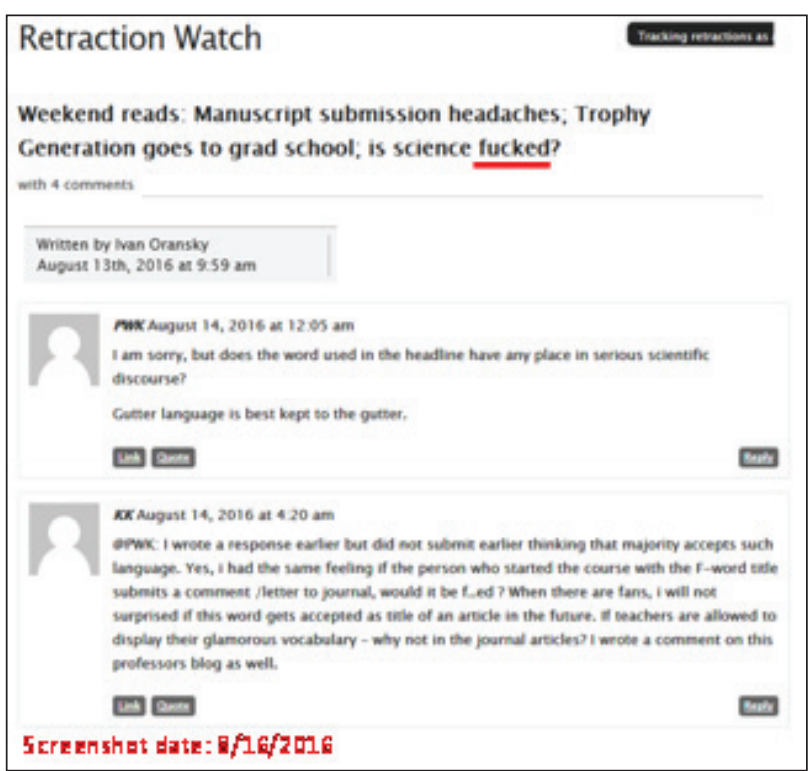

Fig. 5 The use of slang by Retraction Watch's co-founder, Ivan Oransky, draws ire from commentators, one of whom refers to the use fo slang as "gutter language". Red underbar indicates profanity. Screenshot from Oransky (2016).

and trust in the Oransky + Marcus leadership, and sufficient evidence shows that it is an acceptable and popular form of communication by this organization. However, if respectful language cannot be used as part of the journalistic modus operandi, then what other aspects of Retraction Watch need to be carefully analyzed?

\section{Conflicts of interest:}

The author is not associated with any academic institute, blog or web-site. The author was profiled several times, often with issues unrelated to retractions, by Retraction Watch. 


\section{References:}

1. Beall, J. (2014) Bogus journal accepts profanity-laced anti-spam paper. https://scholarlyoa.com/2014/11/20/ bogus-journal-accepts-profanity-laced-anti-spam-paper/ (last accessed: 16 August, 2016)

2. Marcus, A. (2014) Does irony have a place in science? http://retractionwatch.com/2014/12/23/irony-placescience/ (last accessed: 16 August, 2016)

3. Borrell, B. (2016) A bullshit excuse? My lab notebook "was blown into a manure pit". http://retractionwatch. com/2016/01/05/a-new-excuse-for-data-fabrication-mynotebook-blew-into-a-manure-pit/ (last accessed: 16 August, 2016)

4. Oransky, I. (2014) Shigeaki Kato notches retractions 16 and 17, in PNAS. http://retractionwatch.com/2014/01/22/ shigeaki-kato-notices-retractions-16-and-17-inpnas/\#comments (last accessed: 16 August, 2016)

5. Teixeira da Silva, J.A. (2016) Silent or stealth retractions, the dangerous voices of the unknown, deleted literature. Publishing Research Quarterly 32(1): 44-53. DOI: 10.1007/s12109-015-9439-y https://doi.org/10.1007/s12109-015-9439-y

6. Oransky, I. (2016) Weekend reads: Manuscript submission headaches; Trophy Generation goes to grad school; is science fucked? http://retractionwatch. com/2016/08/13/weekend-reads-manuscriptsubmission-headaches-trophy-generation-goes-to-gradschool-is-science-fucked/ (last accessed: 16 August, 2016)

7. Marcus, A. (2016) Beg pardon? Researchers pull cancer paper because, well, um, you see... http://retractionwatch. com/2016/08/10/beg-pardon-researchers-pull-cancerpaper-because-well-um-you-see/\#more-42723 (last accessed: 16 August, 2016)

8. Wikipedia (2016) F word. https://en.wikipedia.org/ wiki/F_word (last accessed: 16 August, 2016) 